\title{
CARDIAC FIBROMA, A RARE PRIMARY TUMOUR- A CASE REPORT
}

\author{
Shubha Sudhakar1, Muktha R. Pai², Thoppil Reba Philipose ${ }^{3}$, Aravind P4
}

${ }_{1}^{1}$ Postgraduate Student, Department of Pathology, AJ Institute of Medical Sciences, Mangaluru, Karnataka, India.

2 Professor and HOD, Department of Pathology, AJ Institute of Medical Sciences, Mangaluru, Karnataka, India.

${ }^{3}$ Professor, Department of Pathology, AJ Institute of Medical Sciences, Mangaluru, Karnataka, India.

${ }^{4}$ Associate Professor, Department of Pathology, AJ Institute of Medical Sciences, Mangaluru, Karnataka, India.

HOW TO CITE THIS ARTICLE: Sudhakar S, Pai MR, Philipose TR, et al. Cardiac fibroma, a rare primary tumour- a case report. J. Evolution Med. Dent. Sci. 2018;7(39):4321-4323, DOI: 10.14260/jemds/2018/963

\section{PRESENTATION OF CASE}

A 5-year-old female child presented with easy fatiguability, fever and chest pain of 2 months' duration, prior to which she was asymptomatic. This rare way of presentation of the child made us document the data. The child was immunised for age. She was active, alert and had attained developmental milestones for her age. On systemic examination, shape of the chest appeared normal with no precordial bulging. On palpation, Apex beat was palpable at left $5^{\text {th }}$ intercostal space at the midclavicular line. There was no evidence of parasternal heave and thrill on examination. First and second heart sounds were heard in all the four cardiac areas and were of normal intensity. Ejection systolic murmur was heard in the $2^{\text {nd }}$ left intercostal space. Echocardiography revealed dilated, well-circumscribed, homogeneous mass attached to the right ventricular outflow tract causing mild obstruction.

Cardiac fibroma, also known as Fibrous hamartoma is a rare primary tumour encountered in infants and children without gender predilection. Fibromas are solitary tumours that are derived from fibroblasts and connective tissue with a matrix containing collagen, located mainly in the ventricular septum.[1] Macroscopically, they present as rounded, white fibrous masses whorled on cut surface. The margin may be either circumscribed or infiltrative. Histologically, fibromas are composed of bland appearing spindle shaped cells arranged in loose intersecting fascicles, which may extend into the surrounding myocardium. A 5-year-old child was referred to the tertiary care hospital, presented with chest pain of 2 months' duration. Echocardiography revealed dilated, homogeneous, well-circumscribed mass attached to the right ventricle with mild right ventricular outflow obstruction. Diagnosis of cardiac fibroma requires a high index of suspicion and correlation with physical and echocardiographic findings. Following surgical excision and histopathological confirmation, the prognosis was excellent.

\section{DIFFERENTIAL DIAGNOSIS}

Cardiac fibromas can be also called as Fibroelastic hamartoma or Fibrous hamartoma. Ventricular masses are uncommon. Cardiac fibromas are the second commonest primary heart tumours after Rhabdomyoma of the paediatric age group. Unlike rhabdomyoma, it can be first diagnosed

'Financial or Other Competing Interest': None.

Submission 10-08-2018, Peer Review 08-09-2018,

Acceptance 14-09-2018, Published 24-09-2018.

Corresponding Author:

Dr. Shubha Sudhakar,

\#301, Inland Echelon, Lokayya Shetty Road

Ballalbagh, Mangalore-575003,

Karnataka, India.

E-mail: shubhmagic@gmail.com

DOI: $10.14260 /$ jemds $/ 2018 / 963$

(c) (1) $(9)$ in elderly. The differential diagnosis in children is a fibrosarcoma. The distinction can be difficult, because fibromas may be cellular in young patients. Sarcomas can be rare in young patients.

\section{CLINICAL DIAGNOSIS}

Cardiac tumours can be benign or malignant neoplasm arising in the myocardium, endocardium or pericardium as a primary site. Clinical observations are rare and different from secondary neoplasms, as $90 \%$ of primary cardiac tumours are benign.

Primary cardiac tumours are less common in infants and children and rare at all ages. These tumours differ in various symptoms, histology and therapy in infancy compared with adulthood. The symptoms depend on the location and usually due to compression of cardiac cavities. Their presentation depends on the location and size of the mass than their histology, as they have the tendency to produce inflow and outflow tract obstruction and arrhythmias.[2] Tumours typical of paediatric age group are Rhabdomyoma, Fibroma and Teratoma, Haemangioma.[3] Fibromas are solitary tumours that is located mainly in the ventricular septum,[1] free wall of left and right ventricle. It has a tendency to grow rapidly. Cardiac fibroma may be a manifestation of Gorlin Syndrome, an autosomal dominant disorder.

\section{PATHOLOGICAL DISCUSSION}

The excised tumour grossly revealed irregular multiple soft tissue bits, totally measuring $6.5 \times 4.5 \times 1.5 \mathrm{~cm}$. On sectioning, the cut surface appeared grey white and had whorled appearance.

Microscopic examination revealed tumour tissue composed of whorls fascicles and loose intersecting bundles of spindle shaped cells.

Spindle cells have tapered nuclei without nucleoli, pale cytoplasm and associated with abundant collagenous stroma. Some of the foci showed prominent, wavy elastic fibres and infiltration of tumour tissue into the adjacent myocardium was seen.

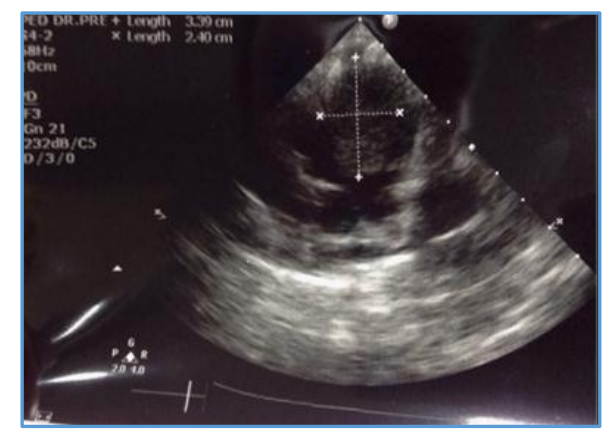

Figure 1. Echocardiography showed Dilated, Homogeneous, Well-Circumscribed Mass attached to Right Ventricle 


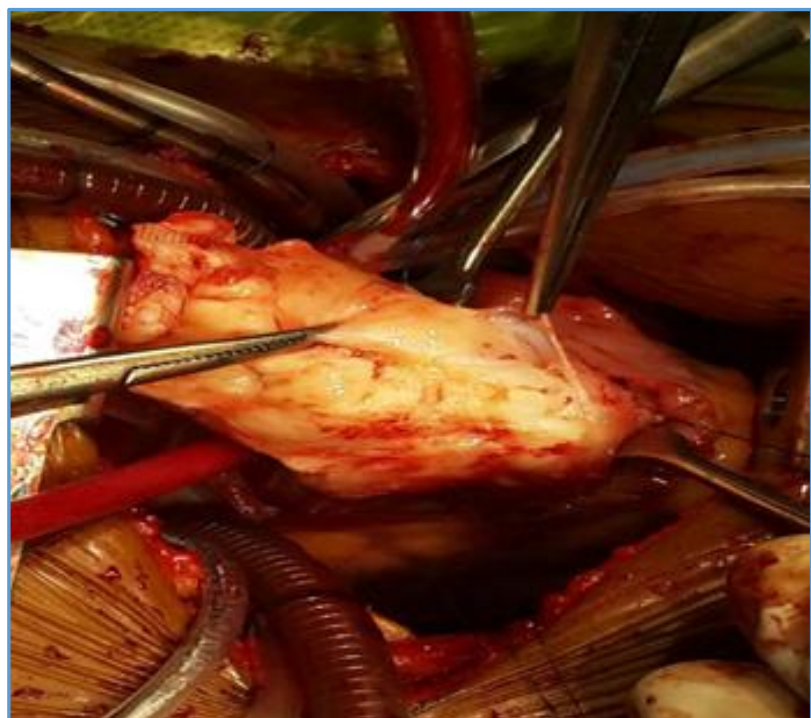

Figure 2. Operative photograph showing the Excision of the Right Ventricular Mass through Median Sternotomy and Pericardial Marsupialisation

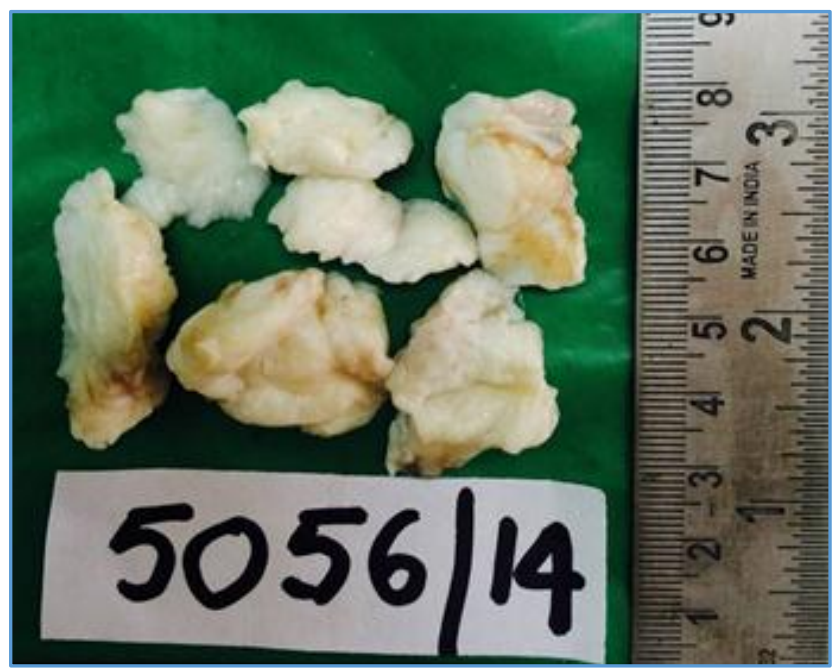

Figure 3. Grey White Irregular Soft Tissue Masses

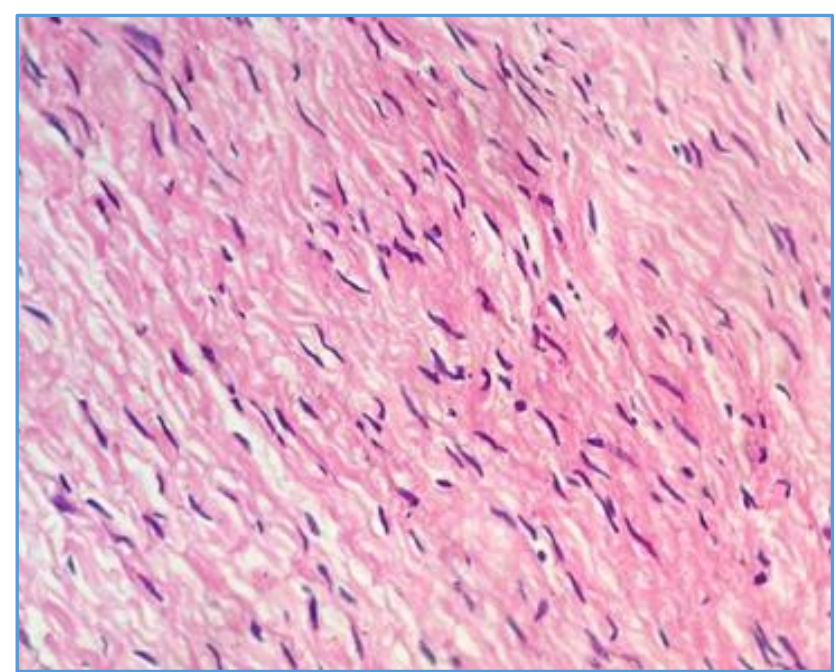

Figure 4. Spindle Cells having Elongated Nuclei, Pale Cytoplasm and Collagenous Stroma (40X)

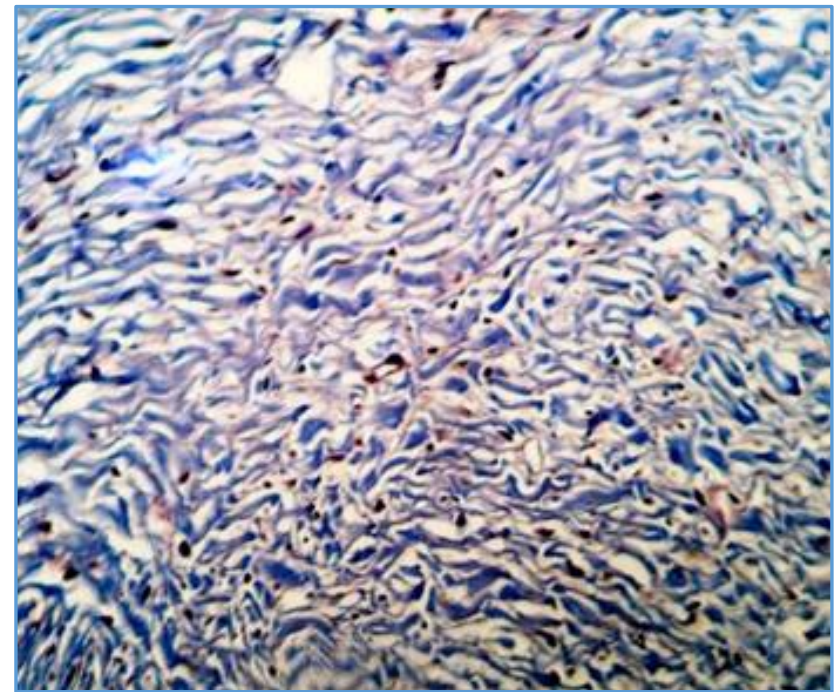

Figure 5. Masson's Trichrome Stain showing Blue Collagen Bundles (40X)

\section{DISCUSSION OF MANAGEMENT}

Intraoperatively, right ventricular, large, fleshy mass was visualised, measuring $7.5 \times 5 \mathrm{~cm}$. Excision of the mass was done through median sternotomy followed by pericardial marsupialisation.

Fibromas are mostly solitary, well-circumscribed, firm, located mainly in the left ventricular free wall and interventricular system. Hence, producing compression of the conduction system, re-entry ventricular arrhythmias or obstruction of ventricular lumen. Sudden death has been reported as one of the manifestations. ${ }^{[4]}$

Microscopically, fibromas are composed of spindle shaped cells with variable amounts of fibrous stroma, entrapment of cardiomyocytes at the periphery and deposits of calcification are frequent. If circumstances are feasible, complete resection is usually recommended. Debulking and heart transplantation in non-resectable forms have been also advocated. ${ }^{[4]}$

Microscopic examination with immunoprofile of cardiac mass is mandatory for the diagnosis, therapy and prognosis. Fibromas are mostly found in ventricles. These can interdigitate with ventricular muscle at the tumour border and replace the functioning muscle mass. They may extend into the ventricular conduction and cause cardiac complications. Cardiac fibromas mostly remain dormant and spontaneous regression rarely occur. Cardiac non-invasive imaging through transthoracic and transoesophageal echocardiography can easily detect the intraventricular mass. There is an increased risk of cardiac fibroma in patients with Gorlin syndrome. Degree of fibrosis increases with age. Degree of cellularity decreases with age.

Kumar et al[5] documented a similar case report of a 3year-old male child that presented with dyspnoea and breathlessness. On Microscopy, showed a benign spindle cell tumour arranged in short fascicles along with areas of hyalinisation and foci of dystrophic calcification was identified. Diagnosis of fibroma was made. Geha et al[6] studied 36 patients with intramural ventricular fibroma, 31 cases occurred in children.

Surgical excision is the mainstay of management and particularly in symptomatic patients. However, follow-up 
with echocardiography is recommended to look for postoperative left ventricular dysfunction or aneurysm. [2]

\section{FINAL DIAGNOSIS}

Cardiac fibroma is a benign neoplasm. Its slow and continuous nature of growth may cause conduction defects.[7] Correlation with physical and echocardiographic findings is important in giving an accurate histopathological diagnosis. The prognosis of cardiac fibroma is excellent with the restoration of best possible haemodynamic function following a complete surgical excision.

Though echocardiography and magnetic resonance imaging are helpful, tumour tissue biopsy or the surgically excised specimens examined by a trained pathologist is crucial in making an accurate diagnosis.

\section{REFERENCES}

[1] Uzun O, Wilson DG, Vujanic GM. Cardiac tumours in children. Orphanet Journal of Rare Diseases 2007;2:11.
[2] Yadava OP. Cardiac tumours in infancy. Indian Heart Journal 2012;64(5):492-6.

[3] Stiller B, Hetzer R, Meyer R, et al. Primary cardiac tumours: When is surgery necessary? Eur J Cardiothorac Surg 2001;20(5):1002-6.

[4] Basso C, Rizzo S, Valente M, et al. Prevalence and pathology of primary cardiac tumours. Cardiovascular Medicine 2012;15(1):18-29.

[5] Kumar N, Sharma S, Ray R, et al. Primary cardiac tumours in a paediatric population: an experience from a tertiary centre with a review of literature. Afr J Paediatr Surg 2014;11(1):44-7.

[6] Geha AS, Weidman WH, Soule EH, et al. Intramural ventricular cardiac fibroma. Successful removal in two cases and review of literature. Circulation 1967;36(3):427-40.

[7] Travis WD, Brambilla E, Muller-Hermelink HK, et al. World Health Organization Classification of Tumours. Pathology and genetics of tumours of the lung, pleura, thymus and heart. Lyon, 2004: p. 268-9. 